\title{
Mirizzi Syndrome: An Experience in Laparoscopic Era
}

\author{
Syed Mukarram Hussain, Asrar Ahmad, Muhammad Awais Mughal, Irum Saleem, Saqib Islam
}

ABSTRACT:

Objective: To assess the presentation and surgical management of Mirrizi syndrome patients who underwent Laparoscopic Cholecystectomy.

Study Design and Setting: Retrospective Descriptive Study was conducted at Surgical Department Combined Military Hospital Rawalpindi and Combined Military Hospital Quetta from 1st Jan 2010 to 20th Jan 2016.

Methodology: Patients undergoing laparoscopic cholecystectomy during this period were retrospectively reviewed. All cases of Mirizzi Syndrome (MS) were identified and data analysed.

Results: A total of 5500 patients underwent laparoscopic cholecystectomy during this period. Approximately 26(0.47\%) cases were identified to be having MS. Out of these 26 cases only 8 (30\%) were males while 18 (70\%) were females. Age ranged from 25 to 80 years. Three patients $(11 \%)$ had an endoscopic retrograde cholangiopancreaticography (ERCP) done. Type-I MS was found in 19 cases (73\%), Type-II in 3 cases (11\%), Type-III and Type-IV in 2 cases each (7.69 \%). Conversion to open surgery was carried out in 15 cases $(57.6 \%)$. All type-I MS had cholecystectomy except one case where partial cholecystectomy was done. T-tube closure of common bile duct was done in all Type-II MS. Similarly Ttube closure was possible in two cases of type-III while one had Roux-en-Y hepaticojejunostomy. All cases of type-IV MS had Roux-en-Y hepaticojejunostomy. One patient out of $26(3.8 \%)$ had carcinoma gallbladder. There was no mortality.

Conclusion: Type-I MS can be managed with laparoscopic cholecystectomy in selected patients.Type-II and type-III MS may need placement of T-tube while most of type-IV MS are managed with Roux-en-Y hepaticojejunostomy.

Key words: Cholecystectomy, Cholangiopancreaticography, Hepaticojejunostomy, Mirizzi Syndrome.

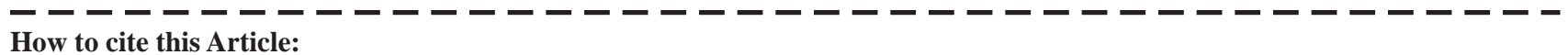

Hussain SM, Ahmad A, Mughal MA, Saleem I, Saqib I. Mirizzi Syndrome: An Experience in Laparoscopic Era . J Bahria Uni Med Dental Coll. 2021; 11(4):165-167 DOI: https://doi.org/10.51985JBUMDC2021027

This is an Open Access article distributed under the terms of the Creative Commons Attribution Non Commercial License (http:// creativecommons/org/licences/by-nc/4.0) which permits unrestricted non commercial use, distribution and reproduction in any medium, provided the original work is properly cited.

- - - - - - - - - - - - - - - - - - - - - - - - - - - - -

\section{INTRODUCTION:}

Gallstone disease is a very common condition mostly affecting fertile females ranging from $11 \%$ to $36 \% .^{1}$ It is most commonly seen in 3rd to 5 th decade of the life. ${ }^{2}$ Symptomatic gallstones can cause a number of complications including mucocele, empyema, xanthogranulomatous cholecystitis, emphysematous cholecystitis, gallbladder wall perforations, pericholecystic abscesses, Mirizzi syndrome,

Syed Mukarram Hussain

Consultant Surgeon, Department of General Surgery

I Combined Military Hospital Peshawar

I Asrar Ahmad

I Consultant, Department of Peads Surgery

PNS Shifa Hospital Karachi

Email: drasrar.ahmad@yahoo.com

Muhammad Awais Mughal

I Consultant, Department of General Surgery

I Combined Military Hospital Mangla

Irum Saleem

I Resident, Department of Gynae/Obs

I PNS SHIFA Hospital, Karachi

I Saqib Islam

Resident, Department of Surgery

INS SHIFA Hospital, Karachi

Received: 24-May-2021

Accepted: 17-Sep-2021 cholecystoenteric fistulas, choledocholithiasis, gallstone pancreatitis, porcelain gallbladder and obstructive jaundice due to the slippage of stones in common bile duct. ${ }^{3}$ Mirizzi syndrome is defined by compression of the common hepatic duct (CHD) by a gallstone either in the Hartmann's pouch or cystic duct with the formation of cholecystobiliary fistula. The clinical features are that of obstructive jaundice, fever, and right upper quadrant pain. Due to the unusual nature of the disease, Mirizzi syndrome is rarely identified preoperatively ${ }^{4}$ It has been reported in the literature that MS is found in $0.3 \%$ to $5 \%$ of all cholecystectomies. ${ }^{5}$

Pablo Mirizzi explained this condition for the first time in detail hence it is named after him. A preoperative diagnosis or identification of MS during open or laparoscopic surgery can forewarn the operating surgeon and is necessary to avoid bile duct injuries in cases of complicated cholecystitis. ${ }^{6}$ In laparoscopic era due to better visibility and appreciation of the anatomy most of the cases are easily diagnosed and promptly treated. Laparoscopic cholecystectomy can safely be attempted in type $1 \mathrm{MS}$ and seems to have fewer overall complications and shorter length of stay compared with an open approach. ${ }^{7}$ General surgeons without long experience in hepatobiliary surgery should refer the patient to a specialized hepatobiliary surgical center. ${ }^{8}$ Therefore; this study was to retrospectively review all the cases of 
laparoscopic cholecystectomy for MS and their management during six years of experience.

\section{METHODOLOGY:}

This study was carried out at the Department of General Surgery, Combined Military Hospital Rawalpindi, Pakistan from $1^{\text {st }}$ January, 2010 to $31^{\text {st }}$ July, 2015 and then at Combined Military Hospital Quetta, Pakistan from $1^{\text {st }}$ August 2015 to $1^{\text {st }}$ February, 2016. All patients including males and females undergoing elective Laparoscopic Cholecystectomy with age ranging from 25-80 years were included. All patients with Acute Biliary Pancreatitis, Empyema Gall Bladder, Gall Bladder perforation and Cholecysto-enteric Fistula were excluded. Prior approval from hospital ethical review committee was taken. Hospital records of all the patients who had laparoscopic cholecystectomy were reviewed. Cases of MS were identified. Patient's demographic data, preoperative investigations, operative procedures carried out and outcome were analysed by using SPSS version-20.

\section{RESULTS:}

A total of 5500 patients underwent laparoscopic cholecystectomy during this period. Out of 5500 only 26 cases were identified to be having MS $(0.47 \%)$. Out of 26 only $8(30 \%)$ were male patients while $18(70 \%)$ were females. The youngest patient was 26 years old while the upper age limit was 80 years. Mean age was 46.5 years. Preoperatively all the cases were investigated with an ultrasound abdomen and liver function tests. Three patients (11\%) were preoperatively identified to be having obstructive jaundice and had an endoscopic retrograde cholangiopancreaticography (ERCP) done to rule out choledocholithiasis. Type-I MS was found in 19 cases (73 $\%)$, Type-II in 3 cases (11\%), Type-III and Type-IV in 2 cases each $(7.69 \%)$. Conversion to open cholecystectomy was done in 15 cases $(57.6 \%)$. Single calculus was found in 4 cases $(15 \%)$ rest were having multiple calculi $(85 \%)$. In all type-I MS, cholecystectomy was possible except one case where partial cholecystectomy was done. Stones were removed from the Hartmann's pouch and it was closed with interrupted absorbable sutures. T-tube closure of common bile duct was done in all Type-II MS. T-tube cholangiogram was carried out on seventh post-operative day and on finding no obstruction it was removed. Similarly T-tube closure was also possible in two cases of type-III while one had Rouxen-Y hepaticojejunostomy. All cases of type-IV MS had Roux-en-Y hepaticojejunostomy. One patient had minor wound infection post-operatively which was managed by laying open the wound and change of dressings. Only one patient out of $26(3.8 \%)$ was found to be having carcinoma gallbladder. The mean post-operative hospital stay was 7 days. There was no mortality.

\section{DISCUSSION:}

Mirizzi syndrome is a very well-known condition which is defined as "obstruction of the common hepatic duct (CHD) due to pressure or compression by a stone lodged in the neck or Hartmann's pouch of the gall bladder." "However, a surgical case of MS has been reported by Milone $\mathrm{M}$ et $\mathrm{al}^{10}$ which was due to acalculous cholecystitis. Since the publication of this case in 2014, we here propose a new definition as "obstruction of the CHD due to compression by the neck or the Hartmann's pouch of the gall bladder."

The incidence of MS reported in the literature during cholecystectomies varies from 0.7 to $1.8 \%{ }^{11,12}$ In this study; MS was among $0.47 \%$ patients. It is almost similar to the findings of $\mathrm{Xu} X \mathrm{XQ}$ et $\mathrm{al}^{13}(0.3 \%)$ but different from Erben $\mathrm{Y}$ et al $(0.18 \%) .{ }^{14} \mathrm{MS}$ is clinically important because it may not be diagnosed preoperatively and during surgery the common bile duct (CBD) or common hepatic duct may be at a high risk of injury. ${ }^{15}$ The most widely accepted classification, Mc Cherry ${ }^{16}$ classified MS into two types in 1982. Type-I concluded only compression of the common hepatic duct while Type-II consisted of the more advanced form of disease with formation of cholecystocholedochal fistula. In 1989 another classification was proposed based on the presence and extent of fistula as follows: ${ }^{17}$

Type I - Compression of CHD by stone impacted at the neck of gallbladder without fistula

(Type II-IV - Cholecystocholedochal Fistula)

Type II- Fistula involving upto one thirds of diameter of CHD

Type III- Fistula involving upto two thirds of diameter of CHD

Type IV- Fistula involving more than two thirds of diameter of CHD

In this study proposed modification of the above classification incorporating MS due acalculous cholecystitis as follows:

Type-I : Compression of CHD without a fistula by the gallbladder neck or Hartmann's pouch

Type-II : Cholecystocholedochal Fistula

Type-IIa: Fistula involving less than half of diameter of CHD

Type-IIb: Fistula involving more than half of diameter of CHD

As this is a more practical classification as far as the treatment is concerned. Type-I cases are managed by partial or complete cholecystectomy by open or laparoscopic surgery. Type IIa cases can be managed by choledochoplasty or T-tube closure but type-IIb cases would require some form of bilioenteric anastomosis.

It was found that MS was associated mainly with multiple small calculi (85\%) rather than single large calculus (15\%) which is frequently thought to be the more common cause. MS can be clinically diagnosed by symptoms of obstructive jaundice with fever and pain in the upper abdomen on right side. ${ }^{18}$ The preoperative diagnosis of MS can be made on 
ultrasonography, ERCP, Magnetic resonance cholangiopancreaticography (MRCP) and percutaneous tranashepatic cholangiography (PTC). ERCP is preferred because it can be therapeutic at the same time as well by removing CBD stones and as placing a biliary stent. ${ }^{11}$ In our study laparoscopic surgery was successful in $42.4 \%$ cases. A systematic review of ten case series carried out by Antoniou SA et al ${ }^{19}$ shows $59 \%$ successful laparoscopic management of MS. However in another retrospective analysis by Erben $\mathrm{Y}$ et $\mathrm{al}^{14}$ laparoscopic surgery was possible in only $33 \%$ cases at Mayo's clinic.

In our series, $3.8 \%$ (one out of 26) patients with MS harboured gallbladder cancer and Parsad TL et $\mathrm{al}^{20}$ has reported an incidence of 5\% ( 7 out of 133 cases) which is almost similar to ours.

\section{CONCLUSION:}

Type-I MS can be managed with laparoscopic cholecystectomy in selected patients.Type-II and type-III MS may need placement of T-tube while most of type-IV MS are managed with Roux-en-Y hepaticojejunostomy.

F Authors Contribution: $-\cdots---\cdots---\cdots$

Syed Mukarram Hussain: Data collection

Asrar Ahmad: Data analysis, write up

Muhammad Awais Mughal: Acquistion of data

I Irum Saleem: Drafting of work

| Saqib Islam: Drafting of work

\section{REFERENCES:}

1. Capoor MR, Nair D, Rajni, Khanna G, Krishna SV, Chintamani MS et al. Microflora of bile aspirates in patients with acute cholecystitis with or without cholelithiasis: A tropical experience. Braz J Infect Dis 2008 ;12: 222-5 DOI: https://doi. org/ 10.1590 /S1413-86702008000300012

2. Shafique MS, Ahmad R, Ahmad SH, Hassan SW, Khan JS. Gallstones in Young Population. Ulutas Med J. 2018;4(3):131138 DOI: https://doi.org/10.5455/umj.20180324011035

3. Gandhi D, Ojili V, Nepal P, Nagar A, Hernandez-Delima FJ, Bajaj D, Choudhary G, Gupta N, Sharma P. A pictorial review of gall stones and its associated complications. Clin Imaging. 2020;60(2):228-236. DOI: https://doi.org/ 10.1016/ j.clinimag. 2019.11.015.

4. Clemente G., Tringali A., Rose AM De, Murazio M., Nuzzo G., Giuliante F. Mirizzi Syndrome : diagnosis and management of a challenging biliary disease. Can. J. Gastroenterol. Hepatol. 2018;2018 DOI: https://doi.org/10.1155/2018/6962090

5. Valderrama-Treviño AI, Granados-Romero JJ, Espejel-Deloiza M, Chernitzky-Camaño J, Mera BB, Estrada-Mata AG, Ceballos-Villalva JC, Campos JA, Argüero-Sánchez R. Updates in Mirizzi syndrome. Hepatobiliary surgery and nutrition. 2017;6(3):170. DOI: https://doi.org/10.21037/hbsn.2016.11.01

6. Tataria RD, Salgaonkar HP, Maheshwari G, Halder PJ. Mirizzi's syndrome: A scoring system for preoperative diagnosis. Saudi J Gastroenterol. 2018;24(5):274-281. DOI: https://doi.org/ $10.4103 /$ sjg.
7. Gelbard R, Khor D, Inaba K, Okoye O, Szczepanski C, Matsushima K, Strumwasser A, Rhee P, Demetriades D. Role of Laparoscopic Surgery in the Current Management of Mirizzi Syndrome. Am Surg. 2018;84(5):667-671. PMID: 29966566. https://doi.org/10.1016/j.jamcollsurg.2016.08.283

8. HAN H, Akhter SQ, Rabbi H, Islam K, Talukder MT, Islam MA. Mirizzi syndrome: diagnosis and management of a challenging biliary disease. BIRDEM [Internet]. 30Dec.2019 [cited 4Apr.2021];10(1):7-DOI: https://doi.org/ 10.3329/ birdem.v10i1.44740

9. Payá-Llorente C, Vázquez-Tarragón A, Alberola-Soler A, Martínez-Pérez A, Martínez-López E, Santarrufina-Martínez S, Ortiz-Tarín I, Armañanzas-Villena E. Mirizzi syndrome: a new insight provided by a novel classification. Annals of Hepato-biliary-pancreatic Surgery. 2017;21(2):67-75. DOI: https://doi.org/10.14701/ahbps.2017.21.2.67

10. Milone, M., Musella, M., Maietta, P. et al. Acute acalculous cholecystitis determining Mirizzi syndrome: case report and literature review. BMC Surg 14, 90 (2014). https://doi.org/ 10.1186/1471-2482-14-90

11. Mishra MC, Vashishtha S, Tandon R. Biliobiliary fistula: preoperative diagnosis and management implications. Surgery. 1990;108(5):835-9. PMID: 2237763.

12. Redaelli CA, Büchler MW, Schilling MK, et al. High coincidence of Mirizzi syndrome and gallbladder carcinoma. Surgery 1997; 121:58. DOI: https://doi.org/10.1016/S00396060(97)90183-5

13. Xu XQ, Hong T, Li BL, Liu W, Xe XD, Zheng CJ. Mirizzi Syndrome: Our experience with 27 cases in PUMC Hospital; Clin Med Sci J. 201;28.172-7.DOI: https://doi.org/ 10.1016 /S1001-9294(13)60044-9

14. Erben Y, Benavente-chenhalls LA, Donohue JM, Que FG, Kendrick ML, Reid-lombardo KM et al. Diagnosis and treatment of Mirizzi syndrome:23 years Mayo clinic experience. J Am Coll Surg 2011; 213.114-9. https://doi. org/10.1016/j.jamcollsurg.2011.03.008

15. Mithani R, Schwesinger WH, Bingener J, Sirinek KR, Gross GW: The Mirizzi syndrome: multidisciplinary management promotes optimal outcomes. J Gastrointest Surg 2008; 12: 1022-28. DOI: https://doi.org/10.1007/s11605-007-0305-x

16. Payá-Llorente C, Vázquez-Tarragón A, Alberola-Soler A, Martínez-Pérez A, Martínez-López E, Santarrufina-Martínez S, Ortiz-Tarín I, Armañanzas-Villena E. Mirizzi syndrome: a new insight provided by a novel classification. Annals of Hepato-biliary-pancreatic Surgery. 2017;21(2):67-75. DOI: https://doi.org/10.14701/ahbps.2017.21.2.67

17. Csendes A, Diaz JC, Burdiles P, Maluenda F, Nava O. Mirizzi syndrome and cholecystobiliary fistula: a unifying classification. Br J Surg 1989; 76:1139-43. DOI: https://doi. org/10.1002/bjs.1800761110

18. Ibrarullah M, Saxena R, Sikora SS. Mirizzi's syndrome: identification and management strategy. Aust N Z J Surg 1993; 63:802. DOI: https://doi.org/10.1111/j.14452197.1993.tb00344.x

19. Antoniou SA, Antoniou GA, Makridis C. laparoscopic treatment of Mirizzzi syndrome: a systematic review. Surg Endosc 2010;24:33. DOI: https://doi.org/10.1007/s00464009-0520-5

20. Parsad TL, Kumar A, Sikora SS. Mirizzi syndrome and gallbladder cancer. J Hepatobiliary Pancreat Surg 2006;13:323. DOI: https://doi.org/10.1007/s00534-005-1072-2 